This item was submitted to Loughborough's Research Repository by the author.

Items in Figshare are protected by copyright, with all rights reserved, unless otherwise indicated.

\title{
Adolescents' experiences and perspectives on physical activity and friend influences over time
}

PLEASE CITE THE PUBLISHED VERSION

https://doi.org/10.1080/02701367.2020.1739607

PUBLISHER

Taylor \& Francis

VERSION

AM (Accepted Manuscript)

PUBLISHER STATEMENT

This is an Accepted Manuscript of an article published by Taylor \& Francis in Research Quarterly for Exercise and Sport on 22 May 2020, available online: http://www.tandfonline.com/10.1080/02701367.2020.1739607.

LICENCE

CC BY-NC-ND 4.0

\section{REPOSITORY RECORD}

Martins, João, António Rodrigues, Adilson Marques, Lorraine Cale, and Francisco Carreiro da Costa. 2020. "Adolescents' Experiences and Perspectives on Physical Activity and Friend Influences over Time". Loughborough University. https://hdl.handle.net/2134/11950092.v1. 
Adolescents' Experiences and Perspectives on Physical Activity and Friend Influences

\section{Over Time}

3

João Martins ${ }^{\mathrm{a}, \mathrm{b}, \mathrm{c}}$, António Rodrigues ${ }^{\mathrm{a}}$, Adilson Marques ${ }^{\mathrm{b}, \mathrm{c}}$, Lorraine Cale ${ }^{\mathrm{e}}$, Francisco Carreiro da Costa ${ }^{b, c}$

${ }^{\text {a}}$ Laboratório de Pedagogia, Faculdade de Motricidade Humana e UIDEF, Instituto de Educação, Universidade de Lisboa, Lisboa, Portugal; ${ }^{b}$ Centro Interdisciplinar do Estudo da Performance Humana, Faculdade de Motricidade Humana, Universidade de Lisboa, Lisboa, Portugal; ' Instituto de Saúde Ambiental, Faculdade de Medicina, Universidade de Lisboa, Lisboa, Portugal; dFaculdade de Educação Física e Desporto, Universidade Lusófona de

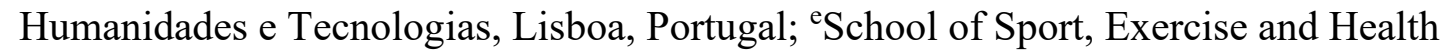
Sciences, Loughborough University, Loughborough, England

\section{Abstract}

Purpose: Understanding friends influences on adolescents' PA, and how these change over time, is fundamental to developing interventions for promoting active lifestyles yet the latter in particular remains unexplored. This study explored the experiences and perspectives of physically active and inactive adolescents regarding the influence of their friends on their PA throughout childhood and adolescence. Methods: Following completion of a questionnaire, 16 adolescents, 8 boys ( 4 physically inactive, 4 active) and 8 girls ( 4 inactive, 4 active), aged $17 \pm 1.0$ years, were selected from two schools. A qualitative design was adopted whereby each adolescent was interviewed individually. Using the constant comparative method, the interviews were inductively and thematically analysed. Results: Four main themes were identified: I) PA journeys; II) Friends provide PA benefits); III) Friends matter in PA, but change; IV) Against all odds - rising above others. Compared to the inactive, active 
adolescents perceived that their friends were fundamental to them becoming and remaining active, specifically in terms of: offering support to internalize an active sense of belonging in different contexts when family support diminished; providing opportunities to be active at key transition points; and helping them to overcome peer victimization. Conclusion: This study confirms the important role of friends in adolescents' PA, and provides new evidence concerning the changing patterns and influence of friends from childhood to late adolescence. Recommendations are made relating to the role of friends in youth PA with a view to improving the effectiveness of approaches to promoting active lifestyles.

Keywords: exercise; friendship; youth; qualitative research.

\section{Adolescents' Experiences and Perspectives on Physical Activity and Friend Influences Over Time}

Despite the potential health benefits of physical activity (PA) (Warburton \& Bredin, 2017), evidence suggests that most adolescents do not meet the recommended 60 minutes of daily moderate-to-vigorous intensity physical activity (MVPA) (Sallis et al., 2016; WHO, 2010), and that PA tends to decrease throughout childhood and adolescence (Cooper et al., 2015). To be more effective in promoting active lifestyles, an improved understanding of which factors are important to PA and how these change over time is needed to better inform PA promotion strategies and the design and timing of PA interventions (Bauman et al., 2012; Jaeschke et al., 2017). role in children and adolescents' PA (Cox, Duncheon, \& McDavid, 2009; Efrat, 2009; Fitzgerald, Fitzgerald, \& Aherne, 2012; Smith, Troped, McDonough, \& DeFreese, 2015).

1 Friends and peers reportedly play an important role in children and adolescents' development, 
52

53

54

55

56

57

58

59

60

61

62

63

64

65

66

67

68

69

70

71

72

particularly in early (12-14 years) and middle (15-17) adolescence, but less so in late adolescence (18-21) (Harter, 2012; Kroger, 2015). Overall, adolescence is seen as a developmental period where autonomy increases, interactions with friends intensify as well as diversify, and during which new social roles are adopted (Brechwald \& Prinstein, 2011;

Heaney \& Viswanath, 2015). Thus, throughout childhood and adolescence friends tend to increase their influence in a number of domains (Brechwald \& Prinstein, 2011; Heaney \& Viswanath, 2015), including PA (Davidson \& Jago, 2009; Salvy et al., 2008; Smith et al., 2015).

Systematic reviews examining the influence of friends on PA (Draper, Grobler, Micklesfield, \& Norris, 2015; Efrat, 2009; Fitzgerald et al., 2012; Maturo \& Cunningham, 2013) highlight several important processes at play, namely: i) social support for PA (emotional or informational actions that friends take to facilitate PA); ii) modeling (having active friends); iii) co-participation; iv) social norms (perceptions of friends' approval for PA); v) friendship quality; vi) social acceptance (how friends feel about a specific individual); vii) crowds affiliation (large groups of peers defined by similar interests); and viii) victimization (target of peers' negative behaviours). Evidence suggests there is a positive association between friends' social support, modeling, and peer crowd affiliation with children and adolescents' PA (Efrat, 2009; Maturo \& Cunningham, 2013; Salvy, Haye, Bowker, \& Hermans, 2012), but a negative relationship regarding peer victimization and PA (Efrat, 2009; Fitzgerald et al., 2012). For adolescents only, friends' co-participation, friendship quality and peer acceptance have been found to be positively associated with PA (Fitzgerald et al., 2012; Maturo \& Cunningham, 2013).

According to O'Sullivan and MacPhail (2010), the growing focus on young people's voices, perspectives and experiences in PA contexts allows researchers to be better placed to acknowledge and address how these can most effectively motivate young people to choose 
active lifestyles. Thus, more recently qualitative and mixed methods studies have been conducted which support the need to focus on adolescents' perspectives in order to gain a better insight into the mechanisms through which friends can influence children's and adolescents' PA experiences (Garcia et al., 2018; Ginis, Nigg, \& Smith, 2013; Smith et al., 2015).

The evidence stemming from systematic reviews of such qualitative studies (Allender, Cowburn, \& Foster, 2006; Martins, Marques, Sarmento, \& Carreiro da Costa, 2015; Maturo \& Cunningham, 2013) reveals the following factors relating to friends to be important in encouraging PA: friends' encouragement for starting a new PA; friends' high PA levels; coparticipation in PA for having fun with friends; spending time together and strengthening social relationships; and friends' positive attitudes towards PA. Conversely, the following factors discourage PA participation: lack of friends' support; physically inactive friends; not doing PA with their friends; and friends who value other leisure activities and that depreciate PA (Allender et al., 2006; Martins et al., 2015; Maturo \& Cunningham, 2013).

Nevertheless, research in this area to date has failed to explore and therefore determine whether there are differences in influence between early, middle, and late adolescence, thereby limiting insight into the connections between friends' PA and adolescent development (Fitzgerald et al., 2012; Martins et al., 2015). Since PA reportedly declines throughout adolescence (Cooper et al., 2015), important implications for promoting active lifestyles can be derived from an increased understanding of the distinct trajectories in friend influence on PA at different childhood/adolescent life stages (Ginis et al., 2013; Jaeschke et al., 2017; Maturo \& Cunningham, 2013), and whether and how pathways differ according to activity status. Moreover, since previous research has primarily been quantitative in nature and restricted largely to adolescents from countries such as the United States, United Kingdom and Australia, to better understand this phenomenon there is a need to conduct qualitative 
102

103

104

105

106

107

108

109

110

111

112

113

114

115

116

117

studies which focus on young people's perspectives and to expand this research into different sociocultural contexts (Fitzgerald et al., 2012; Martins et al., 2015; O'Sullivan \& MacPhail, 2010). Therefore, the present study sought to explore physically active and inactive adolescents' experiences and perspectives on the influence of their friends on their PA throughout childhood and adolescence.

\section{Methods}

\section{Study design, setting and participants}

This study was part of a larger research project, which involved an initial survey of students (170 boys, 217 girls) attending the $12^{\text {th }}$ grade in two schools from very different socio-economic contexts in Lisbon (Portugal). One school was located in an urban and high socioeconomic status area, where most families tend to have good indicators of income, health and education [Instituto Nacional de Estatística, 'National Institute of statistics, INE, 2011]. The other school was located in a suburban area where the majority of families typically have low income and employment rates, low education and diverse ethnic backgrounds (INE, 2011).

The survey gathered information on socio-demographic (e.g. sex, age), behavioural (e.g. PA, leisure time activities), psychological (e.g. perceived competence, perceived health) and educational factors (e.g. attitudes towards school and PE). Using a qualitative design, indepth thematic interviews were conducted with 16 adolescents (mean age of $17 \pm 1.0$ years old) who had responded to the survey. The interviews aimed to capture the context-specific subjective perspectives, meanings and experiences that the participants ascribed to their friends' role in PA from childhood to adolescence.

To address the purpose of the study and to ensure that distinct perspectives were captured, the 16 adolescents were purposefully selected based on the following 
127

128

129

130

131

132

133

134

135

136

137

138

139

140

141

142

143

144

characteristics: PA status (most active, least active/inactive), sex (boy, girl) and socioeconomic status (SES) (high, low). Table 1 shows the demographic and PA characteristics of the 8 boys ( 4 inactive and 4 most active) and 8 girls ( 4 inactive and 4 most active) selected for participation in the interviews. Adolescents' participation in informal PA (i.e. non-structured/guided activities undertaken during leisure/free time), formal PA (i.e. sports activities guided by a teacher/trainer undertaken during leisure/free time that occur outof-school context), school sport (i.e. recreational or competitive activities taken part in within school clubs), and the time per week spent in MVPA were assessed via a questionnaire that has been found to be valid and reliable for the Portuguese context (Ledent et al., 1997). The original intention was to classify active adolescents to be those who reported to do 60 minutes of MVPA daily (WHO, 2010). Given the actual PA levels of the adolescents in the sample, for the purpose of the study the classification of active adolescents needed to be more flexible. Therefore, the most active adolescents were those who reported to participate in MVPA six or more hours per week, on five or more days. As table 1 shows, the most active adolescents reported to be involved in informal PA between one and five days per week and/or formal PA between three and seven days. Three of the most active adolescents said to be involved in school sport between one and three times per week. Conversely, adolescents who reported to spend no time in MVPA were considered physically inactive. Only one adolescent (Rita) reported to dance informally once per week at a low intensity. Further details of the study setting, participants, and research design are described elsewhere (Author et al., 2018).

$$
* * * * * \text { Insert table } 1 \text { here } * * * * *
$$

\section{Data collection}

Each participant took part in a semi-structured interview with the questions centred on the following themes: school sport experiences (not in PE); PA in diverse contexts; friends 
152

153

154

155

156

157

158

159

160 161 (Smith et al., 2015).

162

163

164 adolescents themselves.

and family; childhood and adolescence; and the primary, middle and secondary school phases.

The interview schedule was developed based on the socio-ecological model of health behaviour (Sallis \& Owen, 2015) and the key correlates of PA (Bauman et al., 2012). In this respect, the interview included open-ended questions that sought to establish adolescents' perspectives on several psychological (e.g. attitudes, perceived competence), social (e.g. friends), educational (e.g. school sport) and environmental (e.g. neighbourhood characteristics) factors related to their PA experiences in diverse contexts (e.g. school, sport clubs, neighbourhood) across childhood and adolescence. The relevance of examining PA through an ecological lens has been acknowledged and advocated in a similar previous study

In the present study, emphasis was placed on questions related to the participants' PA experiences outside of PE and the influence of their friends during each distinct life phase (early, middle and late adolescence). This is because the perspectives of the active and the inactive adolescents towards PE were analysed in a previous work (Author et al., 2018).

Examples of questions are as follows: How did you spend your leisure time in primary/middle/secondary school? What positive/negative PA experiences are most memorable? Why? What do you think about the relationship with your friends during your PA experiences throughout childhood/adolescence? What do you think about the role of friends in the adoption and maintenance of an active/inactive lifestyle? The interviews were conducted by the main researcher and lasted between 80 and 120 minutes.

The research was conducted in accordance with the Code of Ethics of the World Medical Association (Declaration of Helsinki). Prior to data collection, approval to conduct the study was obtained from the Portuguese Minister of Education, the National Commission for Data Protection, the schools' principals, the adolescents' legal guardians and the 
Those selected for the interview were invited and informed about the interview purpose and conditions (volunteering, confidentiality and anonymity, audio recorded) and that they had been chosen to participate based on their PA levels. All selected adolescents agreed to be interviewed. The interviews were scheduled to take place during one of their PE lessons. Adolescents' perspectives were facilitated by the following means: ensuring adolescents were fully aware of what their involvement entailed and reinforcing this and the interview purposes and conditions; establishing a welcoming environment (e.g. private room, confortable chairs, water available); giving them legitimate opportunities to speak and respond to all questions; using open-ended questions; actively listening to and refraining from interrupting; and by allowing the adolescents sufficient time to answer, clarify or correct anything said.

\section{Data analysis}

All interviews were transcribed verbatim, coded, and thematically analysed using MAXQDA10 software (VERBI, Germany). Based on the constant comparative method (Corbin \& Strauss, 2008), the interview transcripts were inductively analysed to capture the meaning of the data by one researcher (JM). Specifically, in transcribing the raw data, key elements of the interviews were identified, constantly compared and then coded according to their thematic emphasis. Following this, two researchers (JM, AR) re-examined the data together and the themes were reviewed and confirmed by consensus.

The themes related to PA experiences and friend influences on PA were organized into a chronological sequence (primary school: grades $1-4$, children aged 6-9 years; middle school: grades 5-9, 10-14 years; secondary school: grades 10-12, 15-18 years). Next, a within case analysis allowed a profile to be constructed for each adolescent. This involved close reading of individual interviews and summaries, and identification of a set of significant statements and of themes within each case. Then, a cross-case pattern search using techniques 
202

203

204

205

206

207

208

209

210

211

212

213

214

215

such as group similarities (e.g. most active boys; active girls; inactive boys and inactive girls) and intergroup differences (e.g. active boys vs active girls; active girls vs inactive girls; or active vs inactive adolescents) was conducted to obtain further insight into the data (Corbin \& Strauss, 2008). During the process of data analysis, the differences and diversity in the adolescents' perspectives concerning friend influences on PA throughout childhood and adolescence were explored.

To ensure the study trustworthiness the interview was piloted (Author et al., 2015), regular peer-debriefings for categorical system refinement occurred along the process, and an adequate intra-researcher coding reliability was obtained.

\section{Results and Discussion}

The results are presented and discussed according to the four themes that emerged from the data analysis: I) PA journeys; II) Friends provide PA benefits (active adolescents); III) Friends matter in PA, but change (inactive adolescents); IV) Against all odds - rising above others. These themes highlight the distinct PA pathways the adolescents had experienced and their friends' influence on these throughout their childhood and adolescence.

\section{I) PA journeys (active and inactive adolescents)}

Table 2 summarizes the distinct PA trajectories of the active and inactive participants from childhood through adolescence in informal PA, formal PA and school sport. Active adolescents reported to have mainly participated in diverse positive PA experiences from their early years onwards and until adolescence. During the primary school phase, most of the active adolescents had been involved in school sports and informal PA, and half of them were engaged in formal PA. By the time they reached middle and secondary school, most of the 
active adolescents were already involved in formal PA but only about half of them were doing any informal PA or school sport. The following quotes are illustrative of this:

'As a kid I played karate, football and ran around with my friends. I always liked sport and that is why I was always doing it... I just had to slow down during middle school due to my asthma. However, in secondary school I started to play handball in school sport and after in a sports club. My friends and I have always been very active' (Fábio, active)

'Since I was a kid, I've always played football with friends during school recess. Then, my father took me to play football in a club, I met friends, and I never quit since then. In middle school I was always involved in several PA school tournaments but now I don't do it so often.' (Sérgio, Active)

'I was a very happy child, active and I was always on the street playing with my friends. We played so many things. At fourteen, we didn't play anymore; it was more hanging around. We separated and started to stay at home more. So informal PA was reduced. However, I kept on playing volleyball at school sports club with my friends.' (Ana, Active) $* * * * *$ Insert table 2 here $* * * * *$

in informal PA and formal PA, and half were not involved in school sport experiences. However, in the middle school phase some adolescents claimed to be involved in informal PA, formal PA and school sport. At secondary school, none reported to be engaged in formal PA or school sport. The following quotations illustrate these statements: 
'As a child, my parents sent me to the swimming club for medical reasons. It was a bad experience and I didn't want to be there. I left when I changed school. I've never been involved in any kind of sport because I don't like it.' (José, inativo)

'In my childhood I was involved in some sports because of my parents. In middle school I even got involved in school sport. I went with my friends but it was worthless... Nowadays, I spend my free time with my friends and we don't do much stuff. We like to chat, or play computer or playstation.' (Vasco, Inactive) quit' (Cristina, Inactive).

Overall, the active and the inactive adolescents revealed to have different experiences and perspectives on their PA journeys. The above statements also suggest that active adolescents

267 had more enjoyable PA experiences from an early age, as well as more meaningful 268 interactions with friends in diverse PA contexts.

\section{Friends provide PA benefits (active adolescents)}

Active adolescents talked about their PA experiences alongside their overall

272 development and highlighted the prominent role of friends in this process. Overall, active

273 adolescents spoke about having active friends, receiving encouragement, co-participation, and 274 starting and continuing a new activity with friends across different PA contexts and life 275 phases. For example, Matilde explained: 

'I always did PA with friends. During my childhood I used to play with friends at the playground and we had so much fun together. When I started to dance in primary school, I went with my best friend. When I began to run in a sports club, I met a girl who I became great friends with. Without that best friend, I wouldn't have achieved what I achieved in track and field. [...] Now, I've a friend who is teaching me to play tennis during my free time. I also participate in school tournaments with girls who like to play volleyball. I have always had active friends that have supported me in many ways' (Matilde, active)

From Francisca's perspective, the process of co-participating with friends from an early age and in different informal (school, neighbourhood) and formal (community sports club) contexts, was also present:

I always played football with my friends. After classes I met with them and we went to play. We played in school, in my street or near my friends' houses. As long as there was a good space, we played. Now, it's the same. I play in a club; we go together, and less often in the street. (Francisca, active)

In keeping with earlier findings (Smith, 1999), the active adolescents had established friendships during their early years around PA contexts and their continued relationships seemed to have helped them maintaining their PA over time. Specifically, when reflecting on their primary school years, the majority of active adolescents spoke of a diverse range of PA experiences, namely in informal PA and school sport, where friends had made important contributions in terms of co-participation, modeling and social support, all important processes known to influence PA in childhood (Efrat, 2009). 
Bruno mentioned these influences but at the same time it seems that the perceived

303 social norms negatively influenced his behaviour in some PA contexts (e.g. informal PA at school recess), as he grew older. The importance of this process is also frequently recognised in the literature (Macdonald-Wallis, Jago, \& Sterne, 2012; Salvy et al., 2012). Bruno noted: (Fitzgerald et al., 2012; Sawka, McCormack, Nettel-Aguirre, Hawe, \& Doyle-Baker, 2013). In this study, it was also evident that in the process of developing their identity (Harter, 2012),

'In school what I liked most was recess. We had a field where we played football against all other classes. We challenged each other. We went back to class exhausted and sweating a lot. We loved those moments where we played together [...]. In middle school, during recess, it was more usual to sit around, eat something and talk with friends. Now nobody is active during recess. When you are older you are not supposed to do it, you know...' (Bruno, active)

Thus, as the active adolescents moved from early to middle adolescence, their involvement in informal PA with peers and friends inside and outside school maintained or decreased. However, more adolescents reported to be involved in formal PA. With the increasing sense of autonomy at the end of middle adolescence, active adolescents tended to do other activities prompted by and with their friends in new contexts. Adolescents' increased independence from significant others such as parents (Smith et al., 2015) may have been a factor in encouraging the participants to engage in PA in other contexts away from school or beyond the home at this stage. In addition, research has identified peer crowd affiliation as an important factor for adolescents getting involved in activities and developing their identity the active adolescents had internalized and perceived their friends and social networks to be 
326

327

328

physically active. The following quotes illustrate the above-specified influences on the active adolescents:

'I get involved in school sport club because I always had active friends who did it and encouraged me to do it. I tried once and I didn't leave. What I like the most is to socialize with them and try to give everything to win.' (Ana, active)

'I started to swim with my sister because of my parents. Since childhood my friends have always supported me, mainly the ones from my swimming classes. Especially during middle school, we strengthened our connection and became such good friends until now. As we have more autonomy, we do sports and all other things together - such as going to the cinema, beach, etc. ... It's like a family.' (Sara, active).

Participation in formal activities, such as sport, requires more skills to organize around adolescents' personal and social lives (Harter, 2012; Heaney \& Viswanath, 2015) and this appeared to be the case with the active adolescents in this study, particularly at the end of middle adolescence. Indeed, time management skills and dealing with peer pressure have been found to be important factors that distinguish those who maintain their PA levels from those who do not during adolescence (Martins et al., 2015). The pressure some active adolescents faced, mainly from same sex peers, is evident from the quotes below:

'Others did not help so much. At school some of my female colleagues said quite often: 'but you're still swimming? Just get it over with'. My older group of friends encourage me to continue swimming. But with my peers here at school that's impossible. They just don't get it.' (Sara, active) 
'It's around the $9^{\text {th }}$ grade that you decide if you want to keep doing high level competition sport. It's a new phase in your life where you have more freedom. Friends influence you so much... But I've done sport since I was a little girl. It is an essential part of my life. I don't feel well if I don't do it. Being active is also important for meeting friends and improving social relationships. That's why I never quit doing PA.' (Matilde,

The above quotations highlight that during the initial stages of late adolescence, for being active and staying active the adolescents needed to have time management skills and to make what seems to be an additional effort to manage social relations with their friends.

362 Moreover, their perspectives emphasised the importance of having their friends' encouragement and endorsement for starting new activities, for facilitating their transition within different PA contexts (e.g. from informal to formal PA), and for internalizing and maintaining an active lifestyle. Processes of modeling, co-participation and having fun together, diverse types of encouragement, social norms and logistic support were all at play

367 (Maturo \& Cunningham, 2013; Salvy et al., 2012). Therefore, this study suggests that all 368 these processes should be considered in PA promotion strategies, especially during the middle 369 school phase.

\section{Friends matter in PA, but change (inactive adolescents)}

During their early years, inactive adolescents reported few experiences of participating

373 in informal PA, formal PA or school sport. However, periods of inactivity were sometimes

374 interrupted for a short period if friends 'offered' them opportunities to be active. For example, 375 from previously being inactive the following adolescents revealed: 
'In $5^{\text {th }}$ grade I played volleyball in school. My friends said: 'look, we could all go there and play volleyball'. After one year I stopped. I also played basketball in school sport in $7^{\text {th }}$ grade due to a friend that loved basketball. I never thought to play it but he encouraged me and so I went. Since then I don't remember any friends pushing me to do sport.' (Fernando, inactive)

While Fernando's perspectives were focused on a school sports experience, Tiago talked about his informal PA experiences that took place in his neighbourhood:

'My best friends were from my neighbourhood and we sometimes played football in the street. But one day they moved to live in another town and I stopped doing sport.' (Tiago,

When individuals reached early adolescence, social support from and being in close contact with friends seemed to become increasingly important for the inactive adolescents. In early adolescence, friends operated as the moderators of the participants' social and emotional development creating the necessary 'cliques' and social acceptance for them to get involved in PA. Research shows that the presence of friends is fundamental for getting involved in PA 395 because such joint PA experiences tend to be perceived as more fun, secure, and comfortable 396 and they enable social relationships to be strengthened (Maturo \& Cunningham, 2013; Salvy et al., 2012). However, once such friends disappeared the inactive adolescents' tendencies to dropout increased. Below Leonor described her experiences until the end of early adolescence: 

'My parents never encouraged me to do PA. I'm an inactive girl despite having some active friends. I swam until the end of childhood and played volleyball at school. I went to volleyball because my female friends invited me. [...] Now I prefer listening to music or going to girl scouts. If my friends prompted me it's more likely that I'd do PA. In $10^{\text {th }}$ grade I started to do social dance because a friend invited me to be his partner. I stayed for six months and then he left, and I left too.' (Leonor, inactive)

These statements from inactive adolescents illustrate the instability of their PA depending on their friends' influence at the time. For them, and in accordance with findings in the literature (e.g. Ginis et al., 2013; Salvy et al., 2012), the presence of friends could be a determinant of and affect their PA behaviour in different contexts due to the perceived increased support, fun and motivation they afforded. The converse was also true and without friends' encouragement to do PA it was unlikely that the inactive adolescents would be motivated to participate on a regular basis. Thus, early adolescence seems to be a critical age for PA promotion interventions not only because PA levels tend to decrease during this time (Cooper et al., 2015) but because this is when adolescents seem more receptive to trying and getting involved in new activities with friends.

As in the case of the active adolescents who reported positive feelings and experiences of PA with their friends, the inactive adolescents spoke about the same processes of influence (i.e. social norms, co-participation, modeling) but for 'sedentary' activities. Tiago described his 'sedentary' experiences with his friends as follows:

$$
\text { 'My friends and I have always been too lazy. I never do anything but rest. I like to sleep, }
$$
talk with my friends, and play on the computer. My friends are the best that I could have in life, even more than my family. From $5^{\text {th }}$ to $9^{\text {th }}$ grade I was always with my friends; they 

were like me, lazy and didn't do any kind of PA. I hang around with people who don't do PA and prefer to do 'other stuff'. (Tiago, inactive)

Similarly, José talked about his preference for being sedentary and the support received from his friends to be involved in this type of activities:

'My friends don't do PA. They prefer to play playstation or the guitar. I never needed to do other things than my favourite PA - 'couch potato'. My friends never gave me support or encouraged me to do PA. It's more likely that they tell me to play the guitar.' (José, inactive)

The current study suggests that a friend's preference for, and participation in, sedentary activities might function as a barrier to PA, particularly in the phases of early and middle adolescence (Martins et al., 2015; Sawka et al., 2013). Thus, practitioners should recognise the influence of friends on sedentary behaviours and strive to promote healthy messages such as "move more at any intensity together and sit less" from an earlier phase in the developmental process.

Undoubtedly associated with the general decline in all forms of PA over time, the inactive adolescents reported few PA experiences with friends, primarily in late adolescence. Doing PA with friends was more common in early adolescence and seemed to be particularly relevant for this group, with the joint experiences potentially giving them a favourable sense of self. This finding reinforces the suggestion of Ginis et al. (2013) that early adolescence seems to be a critical period for the timing of PA interventions involving friends.

\section{Against all odds - rising above others (active and inactive adolescents)}


Peer victimization and social isolation have strong associations with poor physical

451 health and may limit involvement in PA (Fitzgerald et al., 2012; Salvy et al., 2012; Smith et al., 2015). Experiences of peer victimization are often reported to have a negative impact on girls' PA involvement (Martins et al. 2015; Stearns, Carson, Spence, Faulkner, \&

454 Leatherdale, 2017). Not surprisingly then, this troubling relationship between peer difficulties 455 and PA, specifically from girls, has been identified as a concern (Li \& Rukavina, 2009; Salvy

456 et al., 2012). The following reported experiences by inactive girls of victimization at school 457 between late childhood until early adolescence are consistent with the findings of previous 458 research:

'I've never practiced any kind of sport. My first PA experience was only when I had PE in the $5^{\text {th }}$ grade. I hated those times in middle school. Everyone begins to change, for girls it's breasts and periods. I didn't like to get changed to do PE, to do exercise in front of them. I

'I don't like to play sport because I don't know how to do it; and the fact that the others were watching us and talking about what you did, you know... I always had that problem. I now try to avoid doing sport and being exposed like that.' (Cristina, inactive) wasn't very good and they didn't want me on their teams. I just liked to stay in the corner with one or two friends pretending that we were really doing something.' (Tânia, inactive)

Despite the negative impact of peer victimization episodes on the PA of adolescents,

472 gender stereotypes in sport or the bullying experiences they encountered. In these cases,

473 modeling and support from some of the adolescents' closest friends were important in helping 474 them to be physically active. With the support of their parents and particularly of their closest 
475 friends, boys included, Francisca, Ana and Sara, all active adolescents, overcame the social

476 norms that 'PA and sport are not for girls' (Clark \& Paechter, 2007). For example, Francisca

477 and Sara respectively said:

478

479 'My female friends used to call me tomboy because I was always playing football with the boys. But I loved to play football with all my friends, boys or girls [...] From $7^{\text {th }}$ to $9^{\text {th }}$ grade I played football in school sport, and I had some female friends there. In school tournaments, it was easy to participate because many of my female friends loved to play sports, but not anymore. Girls don't want to move. I've had to play with boys. They have been always very supportive of me, as opposed to some of the girls.' (Francisca, active)

'Some girls from my school don't understand why I keep swimming at a high competition level. They say I can’t do anything. I disagree. As I said before, my older group of real friends are different. They do understand, support me and make me feel good. When I can't be with them they postpone some of our social activities.' (Sara, active) fundamental support from some of their friends, inclusively from boys, these adolescent girls had built an identity and showed resilience, failing to conform to the dominant and inadequate

494 social norms that 'PA and sport are not for girls'. They overcome the barriers related to name495 calling and peer pressure that came mostly from same sex peers, and continued to participate 496 in PA throughout childhood and adolescence. 
499

500

501

502

503

504

505

506

illustrates how he responded to incidents of peer victimization to become active when, aged

$$
\text { 11, he was subjected to name calling and bullying: }
$$

$$
\text { 'In the } 7^{\text {th }} \text { grade all my classmates were skinny, and I was the only one in the class who }
$$
was fat; they gave me nicknames of "fatty" or "piggy". It started bothering me and I decided to lose weight permanently. I started doing PA with friends. I also had an extra motivation. Girls didn't like fat boys; so to impress them I decided to do PA. Sometimes I spent entire afternoons playing games with some friends of mine, running with them on the beach... At the start of adolescence we committed to playing together. Now it's different, sometimes I run alone in the park but still do capoeira with friends.' (Nelson, active)

Overall, whilst there is evidence to support the negative influence that peer victimization can have on adolescents' PA (Fitzgerald et al., 2012; Li \& Rukavina, 2009; Stearns, Carson, Spence, Faulkner, \& Leatherdale, 2017) it is encouraging to see that some adolescents in this study refuted this. Their ability and confidence to socialize from an early stage of development and to maintain their childhood friends until late adolescence seemed to give them the resilience for retaining their activity over time. Thus, interventions may need to rely on social support (Laird, Fawkner, Kelly, McNamee, \& Niven, 2016)) and take into account the complex gendered power relations in different PA contexts.

\section{Conclusions and practical implications}

The main findings of the present study reveal that the active and inactive adolescents had different PA journeys and perspectives about the role of their friends on their PA.

Compared to the inactive, the active adolescents reported to have experienced more positive experiences in different PA contexts from an early age and to have established friendships 
524 around PA contexts. The stability of the processes of influence such as, co-participation and

525 having fun together, encouragement for doing PA and for starting new activities, and having

526 active friends were considered to be of critical importance by the active adolescents,

527 particularly in early/middle adolescence phase. Time management skills, social skills and

528 friends' support to overcome peer victimization episodes were also identified as important for

529 some of the adolescents to remain physically active, namely girls. Inactive adolescents

530 reported to value and enjoy spending time in sedentary activities with their friends. However,

531 they were also found to be more susceptible to try new physical activities with their friends in 532 early/middle adolescence phase, particularly within the school context.

533 There are several practical implications of these findings for the promotion of active

534 lifestyles in various contexts (e.g. school, physical education, school sport, sport community

535 clubs). PE and PA professionals should have knowledge and understanding of the processes

536 of peer and friend influence on PA and how these are moderated by gender and life-phase. By

537 having a good insight into students' friendships, relationships and social preferences, those

538 practitioners might be in a better position to capitalize on the power of these and work with

539 peer crowd affiliation to boost PA participation. In light of the above, adopting specific

540 grouping strategies which optimize students' interpersonal interactions with friends and peers

541 might help in improving young people's motivation, self-confidence and PA levels (Sawka et

542 al., 2013). Equally, purposefully varying grouping strategies from time to time may prove

543 effective given that adolescents' friendships and interests appear to be transient over time. In

544 addition, understanding the PA behaviours that match the social norms of a valued social

545 group (Brechwald \& Prinstein, 2011; Draper et al., 2015), as well as the social support

546 available, is essential for practitioners to plan realistic targets and intervene to foster positive

547 relationships and reinforce friends' influences on young people's PA. 
The employment of different pedagogical strategies or pedagogical models in different

549 contexts (e.g. physical education, school sport, sport clubs) may also have merit and be used

550 to reinforce and promote cooperation, inclusion, social support and adolescents' PA levels.

551 For example, Gairns, Whipp, and Jackson (2015) advocate the use of relatedness-supportive

552 teaching methods whilst models such as Sport Education and Cooperative Learning (See for

553 example Casey \& MacPhail, 2018) which strive to support the development of various social

554 learning outcomes in young people (e.g. intergroup relations, interpersonal attitudes,

555 communication and listening skills) could in turn help to enhance adolescents' interest and 556 involvement in PA.

557 Particularly, school has been identified as an important context for promoting active

558 lifestyles among children and adolescents (UNESCO, 2015; WHO, 2010). Given that PA

559 declines in early/middle adolescence (Cooper et al., 2015), and the findings from our study

560 suggesting that in this phase the adolescents seem to be more susceptible to starting new

561 activities due to their friends influences, it is critical to consider the different school contexts

562 where PA can be realized and promoted, namely: physical education, before/after school

563 classes, recess, school sport, active commuting and active classes. In doing so, PE teachers

564 should promote positive, fun and meaningful PA experiences that young people can do with

565 their friends. Our study also suggests that in this phase girls may encounter more PA barriers

566 (peer victimization by same sex peers, lack of a friend to participate together) and that boys'

567 social support and co-participation might be a way of overcoming those barriers. Also in the

568 early/middle adolescence phase, the adolescents said to have more autonomy and that were

569 willing to try out-of-school formal PA with their friends. This should be acknowledged by PE

570 teachers in order to facilitate the opportunities and help improve the adolescents' out-of-

571 school formal PA involvement. 
Furthermore and central to all efforts should be the young people themselves and their

573 perspectives (Hill, 2006; Martins et al., 2015; O'Sullivan \& MacPhail, 2010). By conducting

574 in-depth and retrospective interviews with active and inactive adolescents, the complexity of

575 their friends' influences on PA has been captured through their perspectives, thereby adding

576 depth and new insights to previous knowledge (Davidson \& Jago, 2009; Fitzgerald et al.,

577 2012). To better promote active lifestyles it is imperative that adolescents share their

578 perspectives around meaningful issues of direct interest to their lives (O'Sullivan \& MacPhail,

579 2010), and be given the knowledge, skills and confidence to overcome barriers to PA and

580 participate with friends and others in a fun, safe, supportive and inclusive climate (Ginis et al., 581 2013; Martins et al., 2015).

582 The present study has limitations and strengths. As a qualitative study and with only a

583 limited number of participants, the findings may not be widely generalizable across young

584 people and different sociocultural contexts. However, this was not the intention, with the

585 focus being to enhance understanding of the distinct patterns and trajectories in friend

586 influence on PA at different life stages.

With the research design and method of sampling used, the potential for bias and

588 errors in recall should be recognised. To address this, rather than relying on adolescents

589 recalling their experiences, future research could recruit participants at each of the youth

590 development periods. As has been the case in some other studies (e.g. Garcia et al., 2018;

591 Martins et al., 2015), supplementing qualitative research with quantitative data in order to

592 triangulate the findings and friends' influences on children and adolescents PA is also

593 recommended. It should also be acknowledged that some of the adolescents classified as most

594 active in the present study still did not meet the MVPA guidelines (WHO, 2010) (i.e. they did

595 not report to do 60 minutes of MVPA on a daily basis). This therefore needs to be considered

596 when interpreting the findings. 

The authors also acknowledge that by focusing on the social factors related to the role of friends on PA some of the complexity might have been lost. For instance, consideration of the role of parents in PA promotion, especially during childhood and early adolescence. Nevertheless and to counter this somewhat, the adolescents' PA journeys in different contexts were explored and the perspectives presented here portray richness and insight into 602 contrasting influences.

604 adolescents' PA behaviour, and new evidence concerning the changing patterns and influence

605 of friends from childhood through to late adolescence, seemingly helping them to develop, 606 internalize and maintain PA over time. To encourage more children and adolescents to adopt 607 and maintain an active lifestyle it is clearly essential to consider friend influences with respect to gender and life phase and the intersections of both.

\section{What this article adds?}

This article contributes to our understanding of which factors are important to physical activity (PA) and how they change over time to better inform the promotion of PA and/or

613 design and timing of PA interventions with adolescents. The relevance of friends to

614 adolescents' PA participation is well reported in the literature. However, research in this area

615 to date has been mainly quantitative and has therefore failed to adequately consider young 616 people's perspectives, and has been limited in terms of exploring differences in influence

617 between early, middle, and late adolescence. Based on the adolescents' experiences and 618 perspectives, this study has highlighted the following processes through which friends 619 promote physically active lifestyles: stability and continuity in social support and modeling 620 from friends in early and middle adolescence; encouragement and involvement, providing a 621 sense of belonging through participating in PA together; and daily individual and collective 
622

623

624

625

626

627 628

negotiations in early and middle adolescence that provided participants the strength and confidence to challenge, be resilient and rise above peer victimization to be active. Thus, the present study confirms the important role of friends in adolescents' PA. Moreover, the study provides new evidence concerning the changing patterns and influence of friends from childhood to late adolescence, which has important practical implications for improving the effectiveness of promoting active lifestyles amongst adolescents.

\section{References}

Author et al. (2015). Details removed for peer review.

Author et al. (2018). Details removed for peer review.

Allender, S., Cowburn, G., \& Foster, C. (2006). Understanding participation in sport and physical activity among children and adults: a review of qualitative studies. Health Education Research, 21(6), 826-835.

Bauman, A., Reis, R., Sallis, J., Wells, J., Loos, R., \& Martin, B. (2012). Correlates of physical activity: Why are some people physically active and others not? The Lancet, 380, 258-271. doi: 10.1016/S0140-6736(12)60735-1

Brechwald, W., \& Prinstein, M. (2011). Beyond homophily: A decade of advances in understanding peer influence processes. Journal of Research on Adolescence, 21(1), 166-117.

Casey, A., \& MacPhail, A. (2018). Adopting a models-based approach to teaching physical education. Physical Education and Sport Pedagogy. doi: $10.1080 / 17408989.2018 .1429588$

Clark, S., \& Paechter, C. (2007). 'Why can't girls play football?' Gender dynamics and the playground. Sport, Education and Society, 12(3), 261-276. 
646 Cooper, A., Goodman, A., Page, A., Sherar, L., Esliger, D., van Sluijs, E., . . Ekelund, U.

647

648

649

650

651

652

653

654

655

656

657

658

659

660

661

662

663

664

665

666

667

668

669

670

(2015). Objectively measured physical activity and sedentary time in youth: the International children's accelerometry database (ICAD). International Journal of Behavioral Nutrition and Physical Activity, 12. doi: DOI:10.1186/s12966-015-0274-5

Corbin, J., \& Strauss, A. (2008). Basics of qualitative research: Techniques and procedures for developing grounded theory. Thousand Oaks, CA: Sage.

Cox, A., Duncheon, N., \& McDavid, L. (2009). Peers and teachers as sources of relatedness perceptions, motivation, and affective responses in physical education. Research Quarterly for Exercise and Sport, 80, 765-773.

Davidson, K., \& Jago, R. (2009). Change in parent and peer support across ages 9 to 15 and adolescent girls' physical activity. Medicine \& Science in Sports \& Exercise, 41(9), 1816-1825.

Draper, C., Grobler, L., Micklesfield, L., \& Norris, S. (2015). Impact of social norms and social support on diet, physical activity and sedentary behaviour of adolescents: a scoping review. Child: Care, Health and Development, 41(5), 654-667.

Efrat, M. (2009). The relationship between peer and/or friends' influence and physical activity among elementary school children: A Review. Californian Journal of Health Promotion, 7, 48-61.

Fitzgerald, A., Fitzgerald, N., \& Aherne, C. (2012). Do peers matter? A review of peer and/or friends' influence on physical activity among American adolescents. Journal of Adolescence, 35(4), 941-958. doi: 10.1016/j.adolescence.2012.01.002.

Gairns, F., Whipp, P., \& Jackson, B. (2015). Relational perceptions in high school physical education: Teacher- and peer-related predictors of female students' motivation, behavioral engagement, and social anxiety. Frontiers in Psychology, 6, 850. doi: 10.3389/fpsyg.2015.00850 
671 Garcia, J., Sirard, J., Whaley, D., Rice, D., Baker, K., \& Weltman, A. (2018). The influence of friends and psychosocial factors on physical activity and screen time in normal and overweight adolescents: A mixed-methods analysis. American Journal of Health Promotion. doi: 10.1177/0890117118771313

Ginis, K., Nigg, C., \& Smith, A. (2013). Peer-delivered physical activity interventions: an overlooked opportunity for physical activity promotion. Translational Behavioral Medicine, 3(4), 434-443. doi: http://doi.org/10.1007/s13142-013-0215-2

Harter, S. (2012). The construction of the self: Developmental and sociocultural foundations. New York, US: Guilford Press.

Heaney, C., \& Viswanath, K. (2015). Introduction to models of interpersonal influences on health behavior In K. Glanz, B. Rimer, \& K. Viswanath (Eds.), Health Behaviour: Theory, research and practice (5th ed., pp. 151-158). New York, US: John Wiley \& Sons Inc.

Hill, M. (2006). Children's voices on ways of having a voice: Children and young people's perspectives on methods used in research and consultation. Childhood, 13(1), 69-89.

INE. (2011). Census 2011 Resultados definitivos - Região de Lisboa. Lisboa.

Jaeschke, L., Steinbrecher, A., Luzak, A., Puggina, A., Aleksovska, K., Buck, C., . . Pischon, 688 T. (2017). Socio-cultural determinants of physical activity across the life course: a 'Determinants of Diet and Physical Activity' (DEDIPAC) umbrella systematic literature review. International Journal of Behavioral Nutrition and Physical Activity,

692 Kroger, J. (2015). Identity in childhood and adolescence. In J. Wright (Ed.), International Elsevier. 
695

696

697

698

699

700

701

702

703

704

705

706

707

708

709

710

711

712

713

714

715

716

717

718

719

Ledent, M., Cloes, M., Telema, R., Almond, L., Diniz, J., \& Piéron, M. (1997). Participation des jeunes européens aux activités physique et sportives. Sports, 159/160, 61-71.

Li, W., \& Rukavina, P. (2009). A review on coping mechanisms against obesity bias in physical activity/education settings. Obesity Reviews, 10(1), 87-95.

Macdonald-Wallis, K., Jago, R., \& Sterne, J. (2012). Social network analysis of childhood and youth physical activity. American Journal of Preventive Medicine, 43(6), 636642. doi: 10.1016/j.amepre.2012.08.021.

Martins, J., Marques, A., Sarmento, H., \& Carreiro da Costa, F. (2015). Adolescents' perspectives on the barriers and facilitators of physical activity: a systematic review of qualitative studies. Health Education Research, 30(5), 742-755. doi: DOI:10.1093/her/cyv042

Maturo, C., \& Cunningham, S. (2013). Influence of friends on children's physical activity: A review. American Journal of Public Health, 103(7), e23-e38.

O'Sullivan, M., \& MacPhail, A. (Eds.). (2010). Young people's voices in physical education and youth sport. London: Routledge.

Sallis, J., Bull, F., Guthold, R., Heath, G., Ivone, S., Oyeyemi, A., . . Hallal, P. (2016). Physical activity 2016: Progress and challenges. Progress in physical activity over the Olympic quadrennium. The Lancet, 388(10051), 1325-1336. doi:

DOI:10.1016/S0140-6736(16)30581-5

Sallis, J., \& Owen, N. (2015). Ecological models of health behavior. In K. Glanz, B. Rimer, \& K. Viswanath (Eds.), Health behavior. Theory, research and practice (5th ed., pp. 4364). CA, USA: Joissey-Bass.

Salvy, S., Bowker, J., Roemmich, J., R., N., Kieffer, E., Paluch, R., \& Epstein, L. (2008). Peer influence on children's physical activity: An experience sampling study. Journal of Pediatric Psychology, 33, 39-49. doi: 10.1093/jpepsy/jsm039 
Salvy, S., Haye, K., Bowker, R., \& Hermans, C. (2012). Influence of peers and friends on children's and adolescents' eating and activity behaviors. Physiology \& Behaviour, 106(3), 369-378. doi: 10.1016/j.physbeh.2012.03.022

Sawka, K., McCormack, G., Nettel-Aguirre, A., Hawe, P., \& Doyle-Baker, P. (2013).

Friendship networks and physical activity and sedentary behavior among youth: a systematized review. International Journal of Behavioral Nutrition and Physical Activity, 10, 130-139.

Smith, A. (1999). Perceptions of peer relationships and physical activity participation in early adolescence. Journal of Sport \& Exercise Psychology, 21(4), 329-350.

Smith, A., Troped, P., McDonough, M., \& DeFreese, J. (2015). Youth perceptions of how neighborhood physical environment and peers affect physical activity: A focus group study. International Journal of Behavioral Nutrition and Physical Activity, 12, 80. doi: $10.1186 / \mathrm{s} 12966-015-0246-9$

Stearns, J., Carson, V., Spence, J., Faulkner, G., \& Leatherdale, S. (2017). The role of peer victimization in the physical activity and screen time of adolescents: a cross-sectional study. BMC Pediatrics, 17(1), 170. doi: 10.1186/s12887-017-0913-x

Warburton, D., \& Bredin, S. (2017). Health benefits of physical activity: a systematic review of current systematic reviews. Current Opoinion on Cardiology, 32. doi: 10.1097/HCO.0000000000000437

WHO. (2010). Global recommendations on physical activity for health. Geneva: WHO. 
Tables

Table 1. Adolescents' demographic and physical activity characteristics.

\begin{tabular}{|c|c|c|c|c|c|c|c|c|}
\hline \multirow[b]{2}{*}{ Name ${ }^{*}$} & \multirow[b]{2}{*}{$\operatorname{Sex}$} & \multirow[b]{2}{*}{ Age } & \multirow[b]{2}{*}{$\begin{array}{l}\text { Family } \\
\text { SES }\end{array}$} & \multicolumn{5}{|c|}{$\begin{array}{c}\text { PA in adolescence } \\
\text { (based on questionnaire) }\end{array}$} \\
\hline & & & & Lifestyle & $\begin{array}{c}\text { MVPA } \\
\text { (h/week) }\end{array}$ & $\begin{array}{c}\text { Informal } \\
\text { PA } \\
\text { (frequency, } \\
\text { activity) }\end{array}$ & $\begin{array}{c}\text { Formal } \\
\text { PA } \\
\text { (frequency, } \\
\text { activity) }\end{array}$ & $\begin{array}{c}\text { School } \\
\text { sport } \\
\text { (frequency, } \\
\text { activity) }\end{array}$ \\
\hline Matilde & Female & 17 & High & Active & $\geq 7$ & $\begin{array}{l}\text { 3, dance, } \\
\text { walk }\end{array}$ & 5, fitness & - \\
\hline \multirow{2}{*}{$\begin{array}{l}\text { Sara } \\
\text { Ana }\end{array}$} & \multirow{2}{*}{$\begin{array}{l}\text { Female } \\
\text { Female }\end{array}$} & 17 & High & Active & $\geq 7$ & - & 7, swim & - \\
\hline & & 17 & Low & Active & 6 & $\begin{array}{c}5, \\
\text { volleyball, } \\
\text { walk }\end{array}$ & - & $\begin{array}{c}3, \\
\text { volleyball }\end{array}$ \\
\hline Francisca & Female & 18 & Low & Active & $\geq 7$ & $\begin{array}{l}\text { 5, football, } \\
\text { walk }\end{array}$ & 4 , futsal & 3 , futsal \\
\hline \multirow{2}{*}{$\begin{array}{l}\text { Bruno } \\
\text { Sérgio }\end{array}$} & \multirow{2}{*}{$\begin{array}{l}\text { Male } \\
\text { Male }\end{array}$} & 17 & High & Active & $\geq 7$ & 3 , football & 5 , football & - \\
\hline & & 18 & High & Active & $\geq 7$ & $\begin{array}{c}2, \\
\text { swimming }\end{array}$ & 4 , football & - \\
\hline Fábio & Male & 18 & Low & Active & 6 & 1, football & 3 , handball & 1 , handball \\
\hline Nélson & Male & 18 & Low & Active & $\geq 7$ & 1, football & 4 , capoeira & - \\
\hline Leonor & Female & 17 & High & Inactive & 0 & - & - & - \\
\hline Rita & Female & 18 & High & Inactive & 0 & 1 , dance & - & - \\
\hline Cristina & Female & 18 & Low & Inactive & 0 & - & - & - \\
\hline Tânia & Female & 17 & Low & Inactive & 0 & - & - & - \\
\hline Vasco & Male & 17 & High & Inactive & 0 & - & - & - \\
\hline Tiago & Male & 17 & High & Inactive & 0 & - & - & - \\
\hline José & Male & 17 & Low & Inactive & 0 & - & - & - \\
\hline Fernando & Male & 17 & Low & Inactive & 0 & - & - & - \\
\hline
\end{tabular}


Table 2. Informal, formal and school sport physical activity characteristics of participants by phases of life.

\begin{tabular}{|c|c|c|c|c|c|c|c|c|c|c|c|c|c|}
\hline \multirow{3}{*}{ Name* } & \multirow{3}{*}{ Sex } & \multirow{3}{*}{ Age } & \multirow{3}{*}{$\begin{array}{l}\text { Family } \\
\text { SES }\end{array}$} & \multirow{3}{*}{ Lifestyle } & \multicolumn{9}{|c|}{$\begin{array}{c}\text { PA by life phase } \\
\text { (based on interview) }\end{array}$} \\
\hline & & & & & \multicolumn{3}{|c|}{$\begin{array}{l}\text { Informal } \\
\text { PA }\end{array}$} & \multicolumn{3}{|c|}{$\begin{array}{c}\text { Formal } \\
\text { PA }\end{array}$} & \multicolumn{3}{|c|}{$\begin{array}{c}\text { School } \\
\text { Sport }\end{array}$} \\
\hline & & & & & $\begin{array}{l}\text { Primary } \\
\text { School }\end{array}$ & $\begin{array}{l}\text { Middle } \\
\text { School }\end{array}$ & $\begin{array}{l}\text { Secondary } \\
\text { School }\end{array}$ & $\begin{array}{l}\text { Primary } \\
\text { School }\end{array}$ & $\begin{array}{l}\text { Middle } \\
\text { School }\end{array}$ & $\begin{array}{l}\text { Secondary } \\
\text { School }\end{array}$ & $\begin{array}{l}\text { Primary } \\
\text { School }\end{array}$ & $\begin{array}{l}\text { Middle } \\
\text { School }\end{array}$ & $\begin{array}{l}\text { Secondary } \\
\text { School }\end{array}$ \\
\hline Matilde & Female & 17 & High & Active & 0 & 0 & ( & $\bullet$ & 0 & 0 & 0 & $\bullet$ & $\bullet$ \\
\hline Sara & Female & 17 & High & Active & 0 & - & - & 0 & 0 & 0 & 0 & $\bullet$ & - \\
\hline Ana & Female & 17 & Low & Active & 0 & - & - & - & - & $\bullet$ & 0 & $\bullet$ & O \\
\hline Francisca & Female & 18 & Low & Active & 0 & 0 & 0 & 0 & - & O & $\bullet$ & 0 & 0 \\
\hline Bruno & Male & 17 & High & Active & - & - & - & 0 & 0 & 0 & 0 & $\bullet$ & - \\
\hline Sérgio & Male & 18 & High & Active & - & - & - & 0 & 0 & 0 & 0 & 0 & - \\
\hline Fábio & Male & 18 & Low & Active & 0 & 0 & 0 & - & - & 0 & 0 & - & 0 \\
\hline Nélson & Male & 18 & Low & Active & 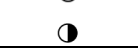 & 0 & 0 & 0 & 0 & 0 & 0 & ( & ( \\
\hline Leonor & Female & 17 & High & Inactive & - & - & - & 0 & - & I & - & 0 & - \\
\hline Rita & Female & 18 & High & Inactive & 0 & - & - & - & - & - & $\bullet$ & - & - \\
\hline Cristina & Female & 18 & Low & Inactive & $\bullet$ & $\bullet$ & - & 0 & 0 & $\bullet$ & 0 & $\bullet$ & - \\
\hline Tânia & Female & 17 & Low & Inactive & - & • & - & - & - & - & - & - & - \\
\hline Vasco & Male & 17 & High & Inactive & 0 & - & - & - & 0 & - & 0 & 0 & - \\
\hline Tiago & Male & 17 & High & Inactive & 0 & 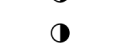 & - & 0 & - & - & $\bullet$ & 0 & $\bullet$ \\
\hline José & Male & 17 & Low & Inactive & - & - & - & $\bullet$ & $\bullet$ & - & 0 & - & - \\
\hline Fernando & Male & 17 & Low & Inactive & $\bullet$ & - & - & e & 0 & 0 & 0 & 0 & $\bullet$ \\
\hline \multicolumn{14}{|c|}{$\begin{array}{l}\text { Abbreviations: SES - Socioeconomic status; Informal physical activity - non-guided activities; Formal physical activity - sports activities guided by a teacher/trainer out-of-school context } \\
\text { School sport - recreational or competitive activities systematically realized in the context of school sports clubs. } \\
\text { Life phases: Primary school (grades } 1 \text { to } 4 \text {, children aged 6-9 years); Middle school (grades } 5 \text { to } 9,10-14 \text { years); Secondary school (grades } 10 \text { to } 12,15-18 \text { years). } \\
\text { Symbols: } \bigcirc \text { Mainly positive/high and/or frequent practice; } \mathbf{Q} \text {, Mainly neutral/moderate and/or intermittent practice; } \bullet \text { Mainly negative and/or low practice. }\end{array}$} \\
\hline
\end{tabular}

